\title{
Preliminary study of superheated steam spray drying: A case study with maltodextrin
}

\section{Fuengfoo, M. ${ }^{\text {a*}}$; Devahastin, S. ${ }^{\text {a. }}$ Niamnuy, C. ${ }^{\text {; }}$; Soponronnarit, S. ${ }^{c}$}

a Advanced Food Processing Research Laboratory, Department of Food Engineering, Faculty of Engineering, King Mongkut’s University of Technology Thonburi, 126 Pracha u-tid Road, Tungkru, Bangkok 10140, Thailand

${ }^{\mathrm{b}}$ Center of Advanced Studies in Industrial Technology, Department of Chemical Engineering, Faculty of Engineering, Kasetsart University, 50 Ngam Wong Wan Road, Chatuchak, Bangkok 10900, Thailand

c Division of Energy Technology, School of Energy, Environment and Materials, King Mongkut's University of Technology Thonburi, 126 Pracha u-tid Road, Tungkru, Bangkok 10140, Thailand

*E-mail of the corresponding author: fengmdf@ku.ac.th

\begin{abstract}
A spray dryer was modified and tested with superheated steam as the drying medium. The effect of the inlet temperature on the recovery and morphology of the dried powder was then investigated. The results were compared with those obtained from hot-air spray drying. The results showed that the use of superheated steam and an increase in the inlet temperature led to an increase in the product recovery. The morphological results correlated with those of the product recovery in that superheated steam powder exhibited more inflated skin, leading to less adhesion of the sprayed droplets to the dryer wall.
\end{abstract}

Keywords: morphology; product recovery; spray drying; superheated steam drying. 


\section{Introduction}

Superheated steam drying is considered to be well established, with many ongoing studies showing that this drying process generally results in products with higher quality, either in terms of physical, chemical or organoleptic properties. ${ }^{[1,2]}$ However, most superheated steam drying studies involved the use of solid samples although in reality many liquid materials also need to be dried. Only a few works are so far available on the use of superheated steam as the medium for drying liquid products, which require the use of, for example, a spray dryer.

The idea of superheated-steam spray drying has been verified mainly only via theoretical analysis or numerical modeling. Frydman et al. ${ }^{[3]}$ and Ducept et al. ${ }^{[4]}$ employed commercial software to simulate the most important features of both superheated steam and hot air spray dryers, including the fields of gas temperature and velocity inside the chamber, droplet trajectories and deposits on the chamber wall. The simulations were experimentally validated by comparing the experimental and simulated residence time distribution of water and $\mathrm{KCl}$ solution droplets in the study of Frydman et al. ${ }^{[3]}$ and Ducept et al. ${ }^{[4]}$, respectively. However, these investigators did not make any attempt to investigate the characteristics of the resulting powder.

Among the limited attempts to study superheated steam spray drying, the works of Islam et al. ${ }^{[5,6,7]}$ exist on the use of vacuum superheated steam spray drying to dry orange juice and orange juice with pulp with maltodextrin as the drying aid. Selected characteristics and properties of powder, i.e., moisture content, hygroscopicity, water activity, particle size, particle morphology, color, rehydration behavior and ascorbic acid retention, produced from the solutions of four different combinations of juice:maltodextrin were studied. Nevertheless, no attempt was made to compare the results with those obtained from a hot air spray dryer at equivalent conditions.

More recently, Lum et al. ${ }^{[8]}$ studied the effect of superheated steam drying on the component migration during the formation of multicomponent droplets. The study was conducted by drying fresh milk droplets in the so-called single droplet drying apparatus; the results were then compared with those belonging to hot-air drying conducted in the same apparatus. The results revealed the possibility of controlling component relocation in a multicomponent droplet based on the improved hydrophilicity of the droplet surface as a result of the use of superheated steam, which is hydrophilic in nature, as the drying medium. By appreciating the potential of superheated steam as the medium for spray drying, engineered multicomponent particles with specific features can be produced.

Despite its potential benefits, no attempt has so far been made to experimentally investigate the effect of superheated steam as the drying medium in a typical (multiple-droplet) atmospheric-pressure spray dryer. No comparison also exists with the results belonging to 
hot-air spray drying at equivalent conditions in terms of the dryer performance and the characteristics of the dried powder.

In the present study, modification was made to an atmospheric-pressure hot-air spray dryer, so it can be used for superheated steam spray drying. Preliminary study was then conducted to investigate the effect of inlet drying temperature on the product recovery; for simplicity, maltodextrin was used as the test material. Morphology of the powder was also observed to support and explain the measured product recovery. The results were compared with those obtained in the case of hot-air spray drying in the same dryer set-up at the same inlet temperatures.

\section{Materials and Methods}

\subsection{Materials}

An aqueous solution (30\% w/v) of maltodextrin (DE 10), which was supplied by Chemipan Corporation Co., Ltd. (Thailand), was prepared by dissolving maltodextrin in distilled water and stirring using a magnetic stirrer at $300 \mathrm{rpm}$ for $30 \mathrm{~min}$.

\subsection{Spray-dryer set-up}

A schematic diagram of the atmospheric-pressure superheated steam spray dryer setup is shown in Fig. 1. A water-tube boiler (Takuma, model TWA-500, Tokyo, Japan), which is able to generate a maximum saturated steam mass flow rate of $500 \mathrm{~kg} / \mathrm{h}$ at a steam pressure of 7 bar (gauge), was used to supply steam to the system. To remove excess moisture from the steam, a steam pocket ( 1 inch in diameter), steam header (4 inches in diameter) and steam separator were used. Thermodynamic steam traps were used to drain excess water from the above three components. The steam pressure was adjusted via the use of a pressure reducing valve (Yoshitake, model GD-30, Tokyo, Japan), which was used to control the steam pressure at near-atmospheric pressure of $20 \mathrm{kPa}$ (gauge). An electric heater rated at $9 \mathrm{~kW}$, which was controlled by a proportional-integral-differential (PID) controller (Omron, model E5CN-RMTC-500, Tokyo, Japan) with an accuracy of $\pm 1^{\circ} \mathrm{C}$, was used to convert saturated steam into superheated steam. A blower was used to deliver the saturated steam to the heater. The steam velocity was adjusted to $14-15 \mathrm{~m} / \mathrm{s}$ by the use of two globe valves; the steam velocity was measured using a pitot tube (Testo, model 445, Lenzkirch, Germany) at point A with an accuracy of $\pm 0.2 \mathrm{~m} / \mathrm{s}$. The inlet steam temperature was varied at 160,170 and $180^{\circ}$ $\mathrm{C}$. The inlet steam temperature as well as the outlet steam temperature were measured at points $\mathrm{B}$ and $\mathrm{C}$, respectively, and were continuously recorded by type $\mathrm{T}$ thermocouples connected to a data logger (Yokogawa, model $\mu$ R100, Tokyo, Japan).

The drying chamber consists of a stainless steel cylindrical chamber, which is $25 \mathrm{~cm}$ in diameter and $50 \mathrm{~cm}$ in height, connected to a bottom conical section of $30 \mathrm{~cm}$ in height. 


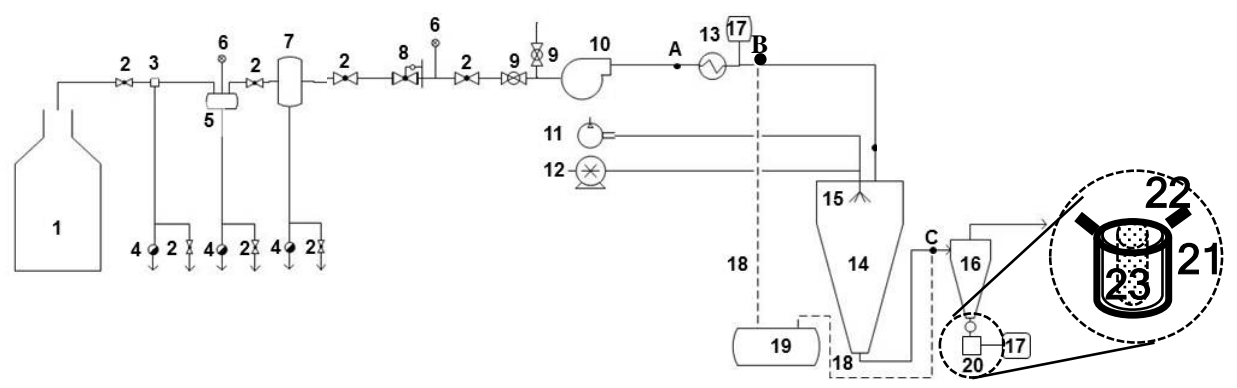

Fig. 1 Schematic diagram of atmospheric-pressure superheated steam spray dryer and associated units: (1) water-tube boiler; (2) globe valves; (3) steam pocket; (4) steam traps; (5) steam header; (6) pressure gauges; (7) steam separator; (8) pressure reducing valve; (9) ball valves; (10) blower; (11) air compressor; (12) liquid feed pump; (13) electrical heater; (14) spray drying chamber; (15) atomizer; (16) cyclone; (17) PID controllers; (18) thermocouples; (19) temperature data logger; (20) powder collector; (21) auxillary heater; (22) steam outlet; (23) cylindrical filter

A two-fluid nozzle with an orifice internal diameter of $1.0 \mathrm{~mm}$ was installed at the top of the drying chamber. The nozzle pressure was maintained at around 2 bar (gauge) during all the spray drying experiments. A glass cyclone, which is $10 \mathrm{~cm}$ in diameter and $20 \mathrm{~cm}$ in height and has the bottom conical section of $30 \mathrm{~cm}$ in height, was used to separate dried powder from the exhaust steam. The dryer can also be operated as a hot-air spray dryer with the use of hot air, which can be supplied to the drying chamber via the use of the blower, as the drying medium.

Maltodextrin solution was fed into the drying chamber via a peristaltic pump (WatsonMarlow, Model 505S, Cornwall, UK) at a feed flow rate of $5 \mathrm{~mL} / \mathrm{min}$. The obtained powder sample was collected and sealed in an aluminum bag until further analysis.

Since the superheated steam spray drying experiments were conducted at atmospheric pressure, there was inevitable steam condensation in the powder collector. To prevent the condensation of steam within the powder collector, an auxillary heater was used to maintain the temperature within the powder collector at around $105^{\circ} \mathrm{C}$; this value is higher than the saturation temperature of the exhaust steam. Moreover, a steam outlet was provided to drain out the exhaust steam. A cylindrical filter made of stainless steel screen of 500 openings per square inch was used to trap dried powder (see an inset in Fig. 1).

\subsection{Analytical methods}

\subsubsection{Product recovery}

The percentage product recovery was calculated by the following equation:

$$
\frac{W_{\mathrm{p}}}{W_{\mathrm{F}}} \times 100 \%
$$


where $W_{\mathrm{p}}$ is the amount of solid mass of the collected powder (g) and $W_{\mathrm{F}}$ is the amount of solid mass of the liquid feed (g).

\subsubsection{Scanning electron microscopy}

The morphology of a spray-dried powder sample was observed via the use of a scanning electron microscope (JEOL, JSM-6400LV, Tokyo, Japan) at an accelerating voltage of 10 $\mathrm{kV}$. Each sample was coated with a gold layer and photographed at 300× magnification level.

\subsubsection{Statistical analysis}

The effects of the type of the drying medium and inlet drying temperature as well as their interactions on the product recovery were determined by the univariate full-factorial analysis of variance (ANOVA). Each experiment was carried out in duplicate. All the experimental data were analyzed using SPSS 16.0 for Windows ${ }^{\circledR}$ (SPSS Inc., Chicago, IL) and are presented as mean values with standard deviations. Differences between mean values were established using Duncan’s new multiple range tests at a confidence level of 95\%.

\section{Results and Discussion}

\subsection{Product recovery}

The effects of the type of the drying medium and inlet temperature on the product recovery were investigated and are shown in Table 1 . The type of the drying medium and inlet drying temperature had a significant effect on the product recovery $(p<0.05)$. However, there were no interactions between the two parameters $(p>0.05)$.

Use of superheated steam as the spray drying medium led to an increase in the product recovery when compared with the use of hot air. This is probably because superheated steam, which has higher heat transfer coefficient and specific heat capacity, could increase the gasdroplet heat transfer rate. The solid surface was more rapidly formed around a droplet during drying, leading subsequently to less adhesion of the sprayed droplets to the drying chamber wall. ${ }^{[9]}$

Table 1. Effect of drying medium and inlet temperature on product recovery

\section{Drying medium Inlet temperature}

\begin{tabular}{cccc} 
& $\mathbf{1 6 0}^{\circ} \mathrm{C}$ & $\mathbf{1 7 0}^{\circ} \mathrm{C}$ & $\mathbf{1 8 0}^{\circ} \mathrm{C}$ \\
\hline Superheated steam & $38.0 \pm 2.82^{\mathrm{b}}$ & $45.0 \pm 1.41^{\mathrm{a}}$ & $48.5 \pm 2.12^{\mathrm{a}}$ \\
Hot air & $32.5 \pm 2.12^{\mathrm{c}}$ & $34.5 \pm 2.12^{\mathrm{bc}}$ & $37.0 \pm 2.82^{\mathrm{b}}$
\end{tabular}

Values with different superscripts are significantly different $(p<0.05)$. 
An increase in the inlet temperature led to an increase in the percentage product recovery. This is because an increase in the drying temperature led to a larger driving force for heat and mass transfer to/from the droplets during drying. ${ }^{[10]}$ This in turn resulted in faster drying and more rapid solid surface formation, leading again to less adhesion of the sprayed droplets to the dryer wall.

\subsection{Particle morphology}

Microstructural characteristics of the powder were investigated, so that the results can be used to support and explain the measured product recovery. Fig. 2 illustrates the effects of the type of the drying medium and inlet drying temperature on the morphology of the maltodextrin powder.

Superheated steam spray-dried maltodextrin powder exhibited overall morphology as larger spherical particles with inflated skin. This indicated that during superheated steam drying, water vaporization took place rapidly and the solid surface was rapidly formed. Besides, it was found that the process conducted at higher temperatures $\left(170^{\circ} \mathrm{C}, 180^{\circ} \mathrm{C}\right)$ resulted in a combination of non-broken particles, fractured spheres and broken shells. Broken shells were due to excessive vaporization of water within the particles during superheated steam drying; such vaporization led to significant volume expansion due to rapid pressure build-up in superheated steam drying and as a result the broken structure if the generated vapor could not move out of the particles fast enough. ${ }^{[2]}$ On the other hand, hot air spray-dried maltodextrin powder exhibited overall morphology as spherical particles with shrivel skin. This is probably due to the results of the slower water evaporation. The skin of the particles remained moist for a longer period of the time, so the particles deflated when vapor condensed within the vacuole as particles were moved into the cooler region of the dryer.

In both the cases of superheated steam and hot air drying, it was found that an increase in the inlet temperature led to a larger size of the dried particles. This is because an increase in the inlet temperature led to a larger driving force for drying to/form the droplets as mentioned earlier. ${ }^{[10]}$ However, it was found that larger particles were obtained in the case of hot air drying than in the case of superheated steam drying at an inlet drying temperature of $160^{\circ} \mathrm{C}$. This is probably due to the fact that the drying temperature of $160^{\circ} \mathrm{C}$ was below the socalled inversion temperature where the drying rate during superheated steam drying was lower than that during hot air drying, leading to the solid surface of particles drying hot air spray drying more rapidly formed than during superheated steam spray drying. 

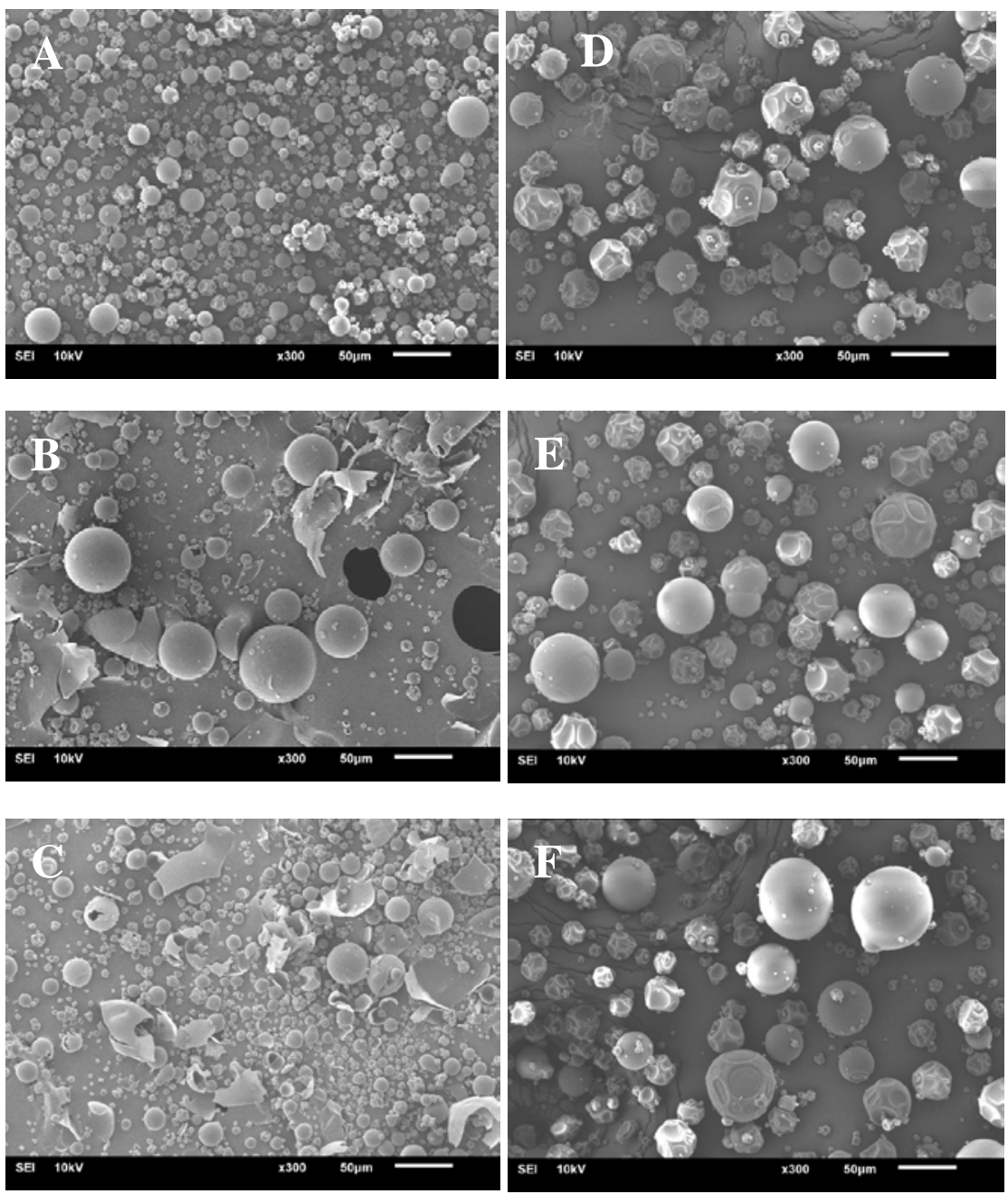

Fig. 2 Morphology of maltodextrin powder dried by superheated steam at (A) $160^{\circ} \mathrm{C},(\mathrm{B}) 170^{\circ} \mathrm{C}$ and $(C) 180^{\circ} \mathrm{C}$; dried by hot air at (D) $160^{\circ} \mathrm{C},(\mathrm{E}) 170^{\circ} \mathrm{C}$ and (F) $180^{\circ} \mathrm{C}$

\section{Conclusions}

Modification was made to an atmospheric-pressure hot air spray dryer to allow the use of superheated steam as the drying medium. Preliminary study was then conducted to investigate the effects of the type of the drying medium and inlet drying temperature on the powdery product recovery. Particle morphology was also evaluated. The use of superheated steam as the drying medium as well as an increase in the inlet temperature could improve the product recovery. The morphological results correlated with the results of the measured product recovery in that superheated steam spray-dried powder was noted as larger spherical 
particles with inflated skin, leading subsequently to less adhesion of sprayed droplets to the dryer wall.

\section{Acknowledgements}

The authors express their sincere appreciation to the Thailand Research Fund (TRF) for supporting the study financially through the Senior Research Scholar Grant (Grant number RTA 5880009) to Author Devahastin and the Distinguished Research Professor Grant (Grant number DPG 5980004) to Author Soponronnarit.

\section{References}

[1] Alfy, A.; Kiran, B.V.; Jeevitha, G.C.; Hebbar, H.U. Recent developments in superheated steam processing of foods-A Review Critical. Reviews in Food Science and Nutrition 2016, 56, 2191-2208.

[2] Devahastin, S.; Mujumdar, A.S. Superheated steam drying of foods and biomaterials. In Modern Drying Technology, Volume 5; Tsotsas, E.; Mujumdar, A.S., Eds.; WileyVCH, Weinheim, Germany, 2014; 57-84.

[3] Frydman, A.; Vasseur, J.; Ducept, F.; Sinneau, M.; Moureh, J. Simulation of spray drying in superheated steam using computational fluid dynamics. Drying Technology 1999, 17, 1313-1326.

[4] Ducept, F.; Sionneau, M.; Vasseur, J. Superheated steam dryer: simulations and experiments on product drying. Chemical Engineering Journal 2002, 86, 75-83.

[5] Islam, M.Z.; Kitamura Y.; Yamano, Y; Kitamura, M. Effect of vacuum spray drying on the physicochemical properties, water sorption and glass transition phenomenon of orange juice powder. Journal of Food Engineering 2016, 169, 131-140.

[6] Islam, M.Z.; Kitamura Y.; Kokawa, M.; Monalisa, K. Degradation kinetics and storage stability of vacuum spray-dried micro wet-milled orange juice (Citrus unshiu) powder. Food Bioprocess Technology 2017, 1002-1014.

[7] Islam, M.Z.; Kitamura Y.; Kokawa, M.; Monalisa, K.; Tsai, F.; Miyamura, S. Effects of micro wet milling and vacuum spray drying on the physicochemical and antioxidant properties of orange (Citrus unshiu) juice with pulp powder. Food and Bioproducts Processing 2017, 101, 132-144.

[8] Lum, A.; Mansouri, S.; Hapgood, K.; Woo, M.W. Single droplet drying of milk in air and superheated steam: Particle formation and wettability. Drying Technology 2018, https://doi.org/10.1080/07373937.2017.1416626.

[9] Chegini, G.R.; Ghobadian, B. Effect of spray-drying conditions on physical properties of orange juice powder. Drying Technology 2005, 23, 657-668.

[10] Nijdam, J.J.; Langrish, T.A.G. An investigation of milk powders produced by a laboratory-scale spray dryer. Drying Technology 2005, 23, 1043-1056. 